\title{
Path Design and Planning and Investment and Construction Mode of Multimodal Transport Network Based on Big Data Analysis
}

\author{
Shuai Wang (iD) and Shaochuan Fu \\ School of Economics and Management, Beijing Jiaotong University, Beijing 100044, China \\ Correspondence should be addressed to Shuai Wang; 16113139@bjtu.edu.cn
}

Received 8 December 2021; Revised 19 January 2022; Accepted 21 January 2022; Published 16 February 2022

Academic Editor: Gengxin Sun

Copyright (C) 2022 Shuai Wang and Shaochuan Fu. This is an open access article distributed under the Creative Commons Attribution License, which permits unrestricted use, distribution, and reproduction in any medium, provided the original work is properly cited.

\begin{abstract}
Currently, long-distance freight transport is shifting towards multimodal transport, the combination of multiple freight transport modes. Multimodal transport enables enterprises with the same logistics function to operate on the same level of the supply chain. Through horizontal cooperation, these enterprises can give play to their advantages, make up their deficiencies, improve service levels, reduce cost input, and thereby enhance market status. Therefore, multimodal transport is an intensive development model that promotes the alliance between giants. The reasonable path design and planning (PDP) and investment and construction mode (ICM) of the multimodal transport network help freight demanders, as well as multimodal freight transport platforms, obtain the maximum profit. Therefore, this paper explores the PDP and ICM of the multimodal transport network based on big data analysis. Firstly, the influencing factors and behavioral features of multimodal transport were deeply examined, drawing on the logit model and the big data on multiple freight services, namely, railway transport, highway transport, waterway transport, and airway transport. After classifying the freights, the authors analyzed the modeling and decision-making of path design and optimization (PDO) for multimodal transport network. The proposed model was proved effective through experiments. This paper theoretically explores the goals, principles, and needs of path selection in the modern transportation industry. In a realistic sense, the research findings help decision-makers optimize their decisions on the multimodal transport network and operate the network at the minimum transport cost.
\end{abstract}

\section{Introduction}

The rapid development of the Chinese economy is mirrored by the burgeoning freight transport and logistics. Internet technology is being integrated with data mining, resulting in various transport projects and platforms that synthetize social information with the diverse big data on freight services and serve the enterprises with freight demand [1-8]. Currently, long-distance freight transport is shifting towards multimodal transport, the combination of multiple freight transport modes [9-13]. Multimodal transport can effectively enhance transport efficiency, reduce freight losses, lower transport costs, and ease traffic congestion [14-24]. As an important means of improving logistics efficiency, the reasonable path design and planning (PDP) and investment and construction mode (ICM) of multimodal transport networks, which rely on the integration of valuable big data on freight services, can reduce the economic and time costs of freight transport to the maximum degree, and help freight demanders, as well as multimodal freight transport platforms, obtain the maximal profit.

Zhao et al. [20] improved the pulse coupling neural network for real-time collision-free path planning of multimodal transport in static and dynamic environments. The improved network considers factors such as transport distance, transport time, and transport cost and combines all the factors into network weights, transforming the path planning problem into the shortest path problem. Lämmel et al. [25] discussed the application of hybrid simulation in large-scale multimodal transport and the evacuation by 
multimodal transport and evaluated the feasibility of using multimodal transport to evacuate some areas in Hamburg, Germany, which are hit by a storm tide.

Multimodal transport is the primary transport mode of low-carbon transport and is a research hotspot in many countries. Liu et al. [26] proposed a multiobjective 0-1 programming model to minimize the total transport cost and the total carbon emissions of transport and demonstrated that the model can effectively retain elite individuals and reduce calculation complexity. To solve the multiobjective optimization in multimodal transport networks, Mnif and Bouamama [27] designed a mathematical model with linear and nonlinear constraints, verified the effectiveness of the model through experiments, and compared the model with the other models in the literature. Focusing on personalized travel planning in big cities with a complex environment, Haqqani et al. [28] put forward an adaptive multicriteria evolutionary algorithm, which integrates passenger preference into travel planning. The proposed algorithm was tested on the dataset of Melbourne, Australia. The test results show that their algorithm can recommend many relevant routes to passengers.

There have been many studies on the costs of multimodal transport. But most of them merely consider the transport fee and transit cost. Very few divide the multimodal transport process into multiple operations. The costs are roughly quantified, failing to reflect the exact proportion of the fee in each link of multimodal transport. The time cost is the major consideration among the previous studies. From different angles, some scholars discussed constraints such as soft time windows, fuzzy time windows, and hybrid time windows and concluded that an elastic time window is more in line with reality.

Starting from the current state and future trend of the freight transport industry in China, this paper summarizes the status quo of multimodal transport in eastern coastal cities, explores the site selection for the nodes of multimodal transport, discusses the actual design and planning of freight transport paths, and stresses the incoordination between the investment and construction mode (ICM) of multimodal transport and regional economic development. On this basis, the authors introduced the goals and significance of exploring the PDP and ICM of multimodal transport through big data analysis and reviewed domestic and foreign research into the features of multimodal transport and the organization modes of freight transport, pointing out the problems and defects of the existing research. To solve these problems and defects, a path design and optimization (PDO) model was designed for multimodal transport networks and proved effective through experiments.

\section{Feature Analysis}

Figure 1 shows the general freight paths of the multimodal transport network, including highway, railway, waterway, and airway transport. It can be seen that the geographical location of nodes plays a critical role in the prediction of freight volume, the site selection of nodes, and the

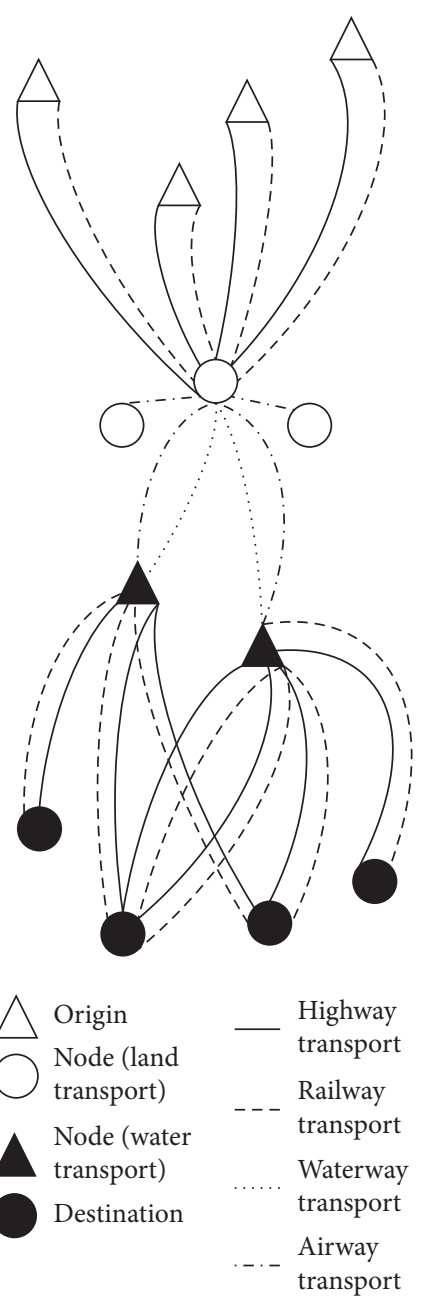

FIGURE 1: Freight paths of the multimodal transport network.

optimization of transport paths in the multimodal transport network. For example, knowing the geographical location, an enterprise can easily find the most economical transport path or storage station. Therefore, this paper first deeply explores the influencing factors and behavioral features of multimodal transport based on the logit model and the big data of various freight transport services (e.g., railway, highway, waterway, and airway).

As a typical discrete choice model, the logit model aims to maximize the utility of the decision on the multimodal transport means. The utility can be characterized by freight cost, storage cost, quality loss cost, and container use cost. In the utility function of the logit model, the independent variables all obey the Gumbel distribution and remain independent. The utility maximization theory is the theoretical basis for making decisions on the multimodal transport mode with the logit model. That is, the freights to be transported are treated as the basic units of logistics behavior and decision-making of multimodal transport. Then, the relevant enterprises would choose the decision with the highest utility.

Let $V_{i m}$ and $V_{j m}$ be the utilities of decisions $i$ and $j$ for freight $m$, respectively, and let $S F_{m}$ be the set of optional 
decisions for multimodal transport. Decision $i$ will be selected for freight $m$ under the following conditions:

$$
v_{i m}>v_{j m}, i \neq j, i, j \in S F_{m} .
$$

The decision utility of multimodal freight transport is a random variable. It is assumed that the decision utility is a function of the following variables: the freight to be transported, the features of decision-making items, and the decisionmaking environment. Let $U_{i m}$ and $\sigma_{i m}$ be the fixed item and random item in the utility function of decision $i$ for freight $m$, respectively. Then, the utility function can be expressed as

$$
v_{i m}=U_{i m}+\sigma_{i m} .
$$

According to the utility maximization theory, the probability $G R_{i m}$ of choosing decision $i$ for freight $m$ can be expressed as

$$
\begin{aligned}
G R_{i m} & =G R\left(v_{i m}>v_{j m}, i \neq j, j \in S F_{m}\right) \\
& =G R\left(u_{i m}+\sigma_{i m}>u_{j m}+\sigma_{j m}\right) \\
0 \leq G R_{i m} & \leq 1, \sum_{i \in S F_{m}}^{m} G R_{i m}=1 .
\end{aligned}
$$

Our goal is to solve the problem of whether the freight demander chooses a multimodal transport decision as the final freight transport mode. There are only two results to this problem: yes $(b=1)$ and no $(b=0)$. Therefore, a binary choice model was selected, in which the dependent variable has two possible values. Let 0 and $U\left(U=\alpha_{0}+\alpha_{1} A_{1}+\alpha_{2} A_{2}+\right.$. . - $\left.+\alpha_{m} A_{m}\right)$ be the utility functions of $b=0$ and $b=1$, respectively. Then, it is easy to estimate function parameters and compare the two kinds of results. The probability of choosing a transport mode at $b=1$ and $b=0$ can be, respectively, calculated by

$$
\begin{aligned}
& G R(b=1)=\frac{e^{u}}{1+e^{u}}, \\
& G R(b=0)=\frac{1}{1+e^{u}} .
\end{aligned}
$$

The final binary selection model for transport modes can be expressed as $V=\alpha_{0}+\alpha_{1} A_{1}+\alpha_{2} A_{2}+\ldots+\alpha_{m} A_{m}+\omega$. For $\alpha_{m} A_{m}, \alpha_{0}, \alpha_{1}, \alpha_{2}, \ldots, \alpha_{m}$ are labeled by the maximum likelihood method and subjected to a significance test. That is, the unknown parameter points of $\alpha_{0}, \alpha_{1}, \alpha_{2}, \ldots, \alpha_{m}$ are estimated.

The different features and organization modes of different freight transport modes must be considered during the PDP and ICM of the actual multimodal transport network. Figure 2 illustrates the organizational modes of multimodal transport. In the multimodal transport network of China, highway transport has several advantages over railway transport and airway transport: high flexibility, complete network coverage, and few time constraints. The railway and airway networks in China are not yet mature and constrained by fixed time windows. With a long transport cycle, waterway transport applies to freights with a relaxed delivery period.
At any node, the transport path can be selected under the assumption that the node is always ready to transport the freight, or in the light of the single time window of the node or delivery period. This traditional approach can complete the design and planning of the multimodal transport network. But its results deviate from the actual transport situation and impact the economic returns of investment and construction.

To make more realistic decisions of multimodal freight transport, multiple fixed time windows for freight services were deployed at the nodes, reflecting the different features and organizational modes of different freight transport modes. Figure 3 provides an example of the time window for freight services.

Let $\left[r_{i}^{l}, s_{i}^{l}\right]$ be the time window for transport mode $l$ to serve node $i, r_{i}^{l}$ be the lower bound of the time window, i.e., the start time for the vehicle to arrive at node $i$ and provide transport service, and $s_{i}^{l}$ be the upper bound of the time window, i.e., the end time for the vehicle to leave from node $i$ and cease to provide transport service. Then, the relationship between the time $E_{i}$ of the arrival of the freight at node $i$ and the time window for freight services can be described as follows:

(a) If the freight to be transported arrives early at node $i$, i.e., $E_{i}<r_{i}^{9}$, the time window for freight services is not yet open, and a waiting time $\theta_{i}^{\varphi}=r_{i}^{l}-E_{i}$ will be generated

(b) If the freight to be transported arrives at node $i$ within the time window, the transport modes can be converted directly, and the waiting time $\theta^{\varphi}{ }_{i}=0$

(c) If the freight to be transported arrives late, i.e., $E_{i}>r_{i}^{l}$, it is necessary to wait for the next time window of freight services

The conversion time $\varphi_{i}^{l k}$ from transport mode $l$ to transport mode $k$ at node $i$ cannot be ignored in actual multimodal transport decisions. That is, any conversion between transport modes and loading/unloading of freights cannot proceed before the arrival of the vehicle.

The multimodal transport network has a stricter time requirement than a single transport mode. The shortest transport time is a common objective in the design or path optimization of the multimodal transport network. However, there is often an inventory cycle at the destination. If the freight arrives early, it needs to wait until the destination has sufficient storage space. If the freight arrives late, freight supply and idle inventory will ensue. In other words, early or late delivery of the freight brings economic losses, which can be measured by discount coefficients.

Under the effect of the delivery period and inventory cycle, the satisfaction of the consignor and consignee is not proportional to the delivery period. Hence, this paper describes the time window of the delivery period based on the trapezoidal fuzzy number.

Let $[o \psi, o]$ be the consumption period of turnover inventory at the destination. Based on the fuzzy membership function $v\left(\psi_{p-t}\right)$, the satisfaction of the consignor and consignee can be characterized by 


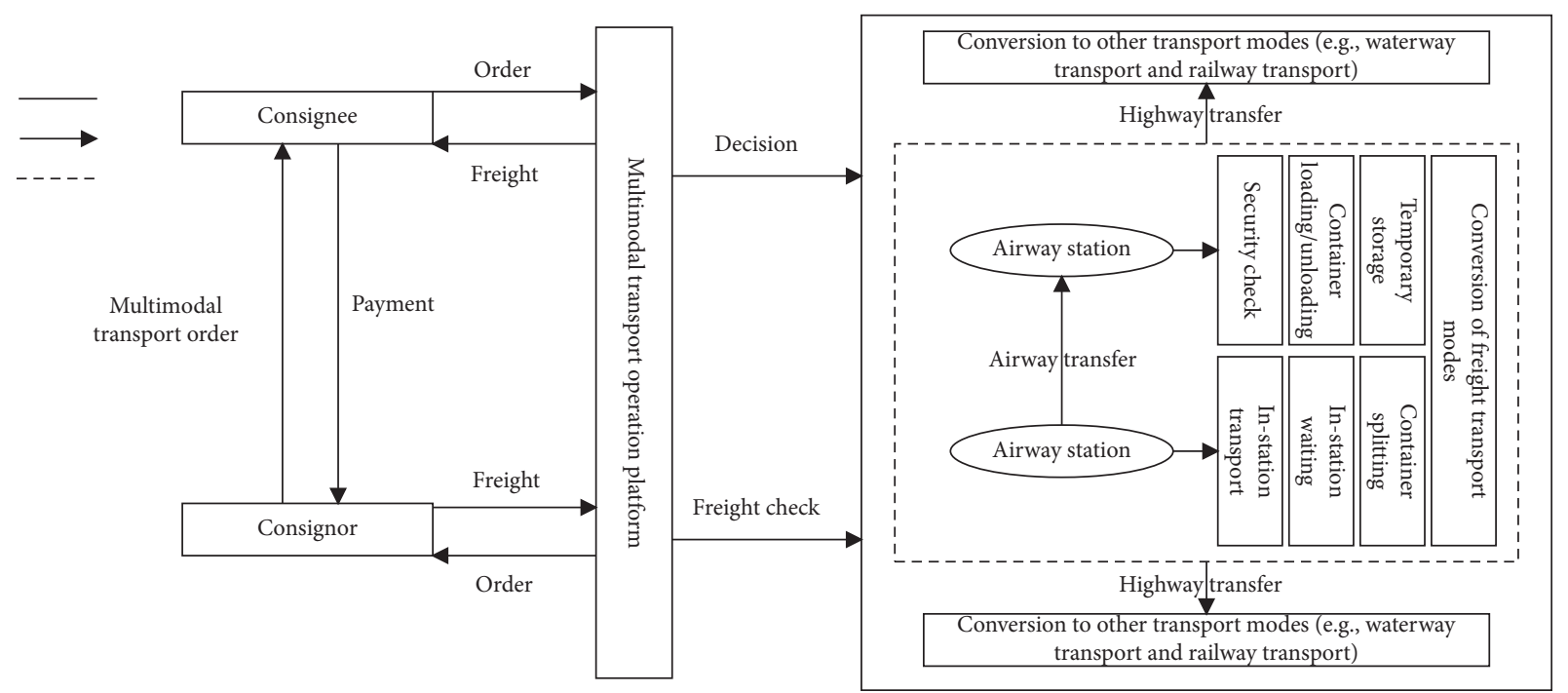

FIgURE 2: Organizational mode of multimodal freight transport.

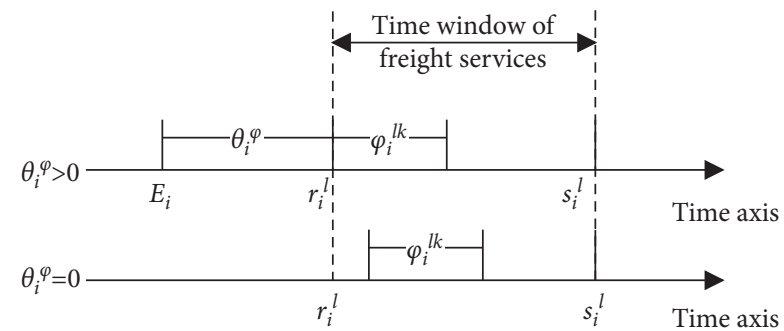

Figure 3: Time window for freight services.

$$
v\left(\psi_{p-t}\right)=\left\{\begin{array}{l}
\frac{\psi_{p-t}-o \psi}{o-o \psi}, o \psi<\psi_{p-t}<o ; \\
\frac{k \psi-\psi_{p-t}}{k \psi-k}, o \leq \psi_{p-t} \leq k ; \\
0, \quad \text { otherwise }
\end{array}\right.
$$

where $[o \psi, o]$ is the consumption period of turnover inventory to ensure the normal freight supply between two replenishments. During $[o \psi, o]$, the inventory cost of the freight arriving at the destination decreases with the consumption of the inventory. Meanwhile, the satisfaction of the consignor and consignee both improves. Thus, we have

$$
\frac{\psi_{p-t}-o \psi}{o-o \psi} .
$$

Let $[o, k]$ be the optimal delivery period, in which the satisfaction of the consignor and consignee with freight delivery is both 1 , and $[k, k \psi]$ be the safe inventory consumption period of the consignee. If the freight arrives later than $k$, the safe inventory will be consumed. In this case, freight supply might be affected, pushing up the shortage cost. Inventory consumption has a great impact on the consignee. Hence, the satisfaction of the consignee with freight delivery drops relatively apparently. Thus, we have

$$
\frac{k \psi-\psi_{p-t}}{k \psi-k}
$$

If the freight arrives beyond the time window [o $\psi, \mathrm{k} \psi]$, then the satisfaction of the consignor and consignee will drop to 0 .

\section{PDO Model}

The multimodal transport operation platform stores a huge number of various freight service data. Through data mining, it is possible to acquire valuable data and obtain analysis results that benefit the platform operation. Figure 4 presents the architecture of the multimodal freight transport platform based on data mining. It can be inferred that the data mining techniques of the platform mainly cover the freight attribute analysis and freight classification in the data preprocessing phase and the modeling and decision-making in the PDO phase. The latter phase is the focus of this research.

3.1. Freight Cost Analysis. Facing a limited delivery period, multimodal freight transport incurs two types of costs: the in-transit cost of the vehicle and the conversion cost of transport modes. The former directly depends on transport speed and transport distance, and the latter could be characterized by the loading/unloading fee during the conversion between transport modes. Let $U$ be the set of all nodes in the network; $O$ be the set of transport mode conversions in the network; $L$ be the set of transport modes; $W_{m}$ be the volume of type $m$ freights; $\delta_{i, j}{ }^{l}$ be the transport distance of mode $l$ between nodes $i$ and $j ; d_{i, j}{ }^{l}$ be the unit transport cost of mode $l$ between nodes $i$ and $j$; and $d_{i}^{l, k}$ be the unit conversion cost between mode $l$ and mode $k$ at node $i$. Then, the cost of multimodal freight transport can be expressed as 


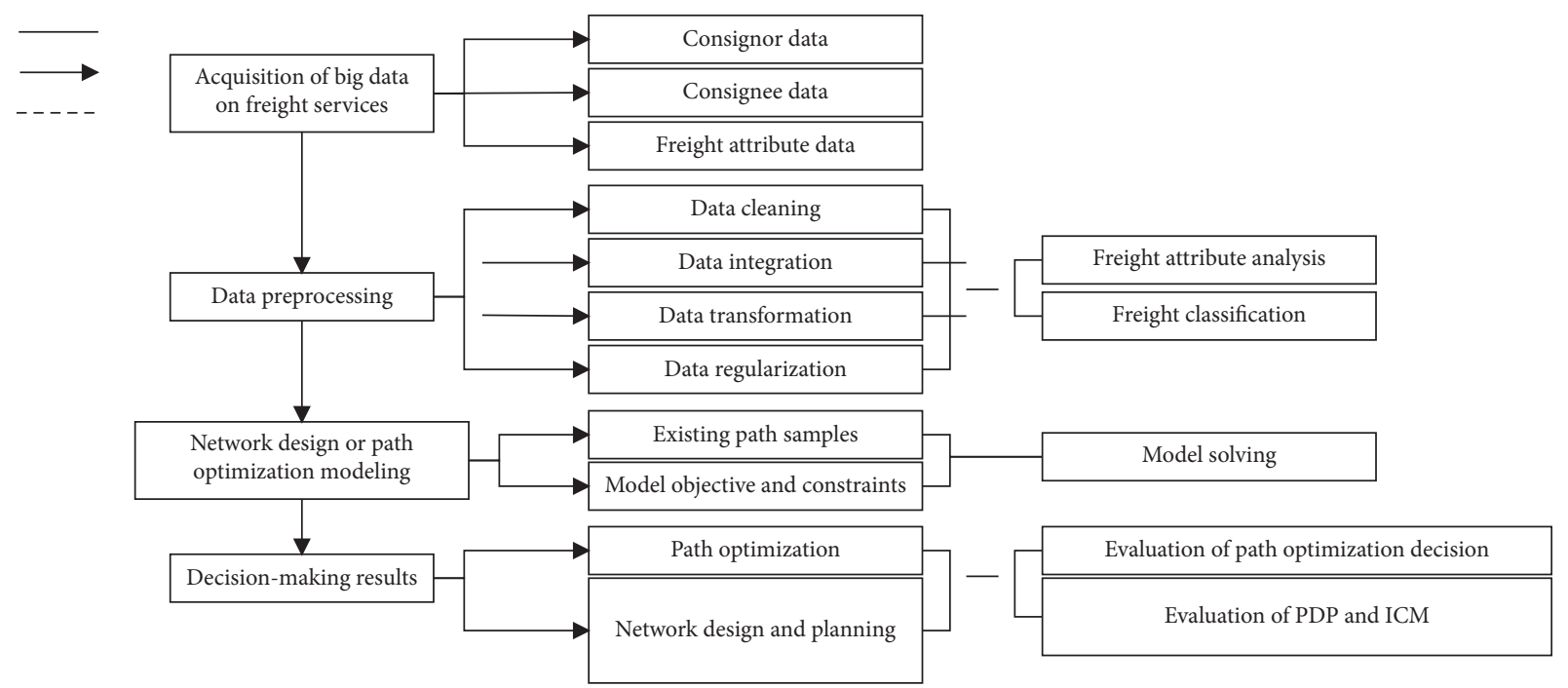

FIgURE 4: Architecture of the multimodal freight transport platform based on data mining.

$$
D_{1}=\sum_{m} \sum_{i, j \in U} \sum_{l \in L} W_{m} a_{i, j}^{l} d_{i, j}^{l} \delta_{i, j}^{l}+\sum_{m} \sum_{i \in O} \sum_{l \in L} W_{m} b_{i}^{l, k} d_{i}^{l, k}
$$

where $A_{i, j}^{l}$ and $b_{i, j}^{l}$ are binary variables:

$$
\begin{aligned}
a_{i, j}^{l} & =\left\{\begin{array}{l}
1, \text { if mode } l \text { is adopted between } \mathrm{i} \text { and } \mathrm{j} \\
0, \text { otherwise }
\end{array}\right. \\
b_{i}^{l, j} & =\left\{\begin{array}{l}
1, \text { if mode } \mathrm{l} \text { is converted to mode } \mathrm{k} \text { at } \mathrm{i} \\
0, \text { otherwise }
\end{array}\right.
\end{aligned}
$$

Before the time window for freight services is open at node $i$, if the freight arrives earlier than the planned time at node $i$, an inventory waiting time and a freight storage cost would appear. Let $\xi_{i}$ be the unit freight storage cost and $\theta_{i}{ }^{\varphi}$ be the waiting time. The freight storage cost can be expressed as

$$
D_{2}=\sum_{i \in O} \sum_{l \in L} \xi_{i} \theta_{i}^{\phi} b_{i}^{l, k}
$$

$\theta_{i}^{\varphi}$ can be calculated by

$$
\theta_{i}^{\phi}=\max \left(r_{i}^{l}-E_{i}, 0\right) \text {. }
$$

If the in-transit time is too long, the quality of the freight will deteriorate, bringing a loss to the consignee. This loss can be regarded as a quality loss cost related to freight production cost. This paper introduces a discount factor $\sigma \in[0,1]$ to characterize the proportion of unit quality loss to total production cost loss. Let $d_{m o}, \mu_{m}, \psi_{m X}$, and $U D_{m}$ be the unit production cost, acceptance rate, shelf life, and quality degradation point of type $m$ freights, respectively. Then, the quality loss cost of freight can be calculated by

$$
D_{3}=\sigma \sum_{m} W_{m} d_{m o}\left(1-\mu_{m}\right) \text {. }
$$

Let $\psi_{p-t}$ be the total transport time on the paths decided for the multimodal transport network. Then, $\mu_{m}$ can be calculated by

$$
\mu_{m}=\min \left\{\frac{1-\psi_{p-t} / \psi_{m X}}{1-U D_{m}}, 1\right\} .
$$

$\psi_{p-t}$ can be calculated by

$$
\psi_{p-t}=\sum_{i, j \in U} \sum_{l \in L} \phi_{i, j}^{l} a_{i, j}^{l}+\sum_{i \in U} \sum_{l, j \in L} b_{i}^{l, k}\left(s_{i}^{l}-E_{i}\right) .
$$

Formula (16) shows that $\psi_{p-t}$ is the sum of the total intransit time and the total mode conversion time at node $i$. Let $u_{i, j}{ }^{l}$ be the mean speed of mode $l$ between nodes $i$ and $j$. Then, the transport time $\varphi_{i, j}^{l}$ of mode $l$ between nodes $i$ and $j$ can be calculated by

$$
\phi_{i, j}^{l}=\frac{\delta_{i, j}^{l}}{u_{i, j}^{l}} .
$$

Freights with a tight delivery period require highquality loading. Considering the special freight conditions of airway and railway transport, a proper loading unit should be selected as per freight attributes before the transport. Concerning freight loading in airway and railway transport, this paper recommends loading the freights with a tight delivery period into small containers. As per the specific requirements, airway and railway transport could use electric, one-time, or reusable thermostat containers or refrigerated containers. All containers are transported and transited along with the freights through multimodal transport. After the completion of freight transport, the containers will be recycled and reused. The one-time thermostat or refrigerated containers only incur a rental cost and an insulation/ cooling cost. These containers are relatively popular and can work continuously for $10 \mathrm{~h}$. Let $m_{w}$ be the number of containers used for type $m$ freights; $d_{f}$ be the daily rental cost per container; $d_{o}$ be the freight storage cost per container; and $R O\left({ }^{*}\right)$ be the round up function. Then, the cost of using this type of container in multimodal transport can be calculated by 


$$
D_{4}=\sum_{m} w_{m}\left[d_{f} * R O\left(\frac{\psi_{p-t}}{24}\right)+d_{o} * R O\left(\frac{\psi_{p-t}}{10}\right)\right] .
$$

Let $n$ be the freight weight that a container can carry. Then, $w_{m}$ can be calculated by

$$
w_{m}=R O\left(\frac{W_{m}}{n}\right)
$$

3.2. Modeling. According to the above analysis on the costs and parameters of multimodal transport networks, an objective function can be constructed for the network design or path optimization of a multimodal transport network facing multiple time windows and various transport services. Let $C$ be the total cost of the paths in the multimodal transport network. Then, the objective function can be expressed as

$$
\begin{aligned}
& \min C= D_{1}+D_{2}+D_{3}+D_{4} \\
&= \sum_{m} \sum_{i, j \in U} \sum_{l \in L} W_{m} a_{i, j}^{l} d_{i, j}^{l} \delta_{i, j}^{l}+\sum_{m} \sum_{i \in O} \sum_{l \in L} W_{m} b_{i}^{l, k} d_{i}^{l, k}+\sum_{i \in O} \sum_{l \in L} \xi_{i} \theta_{i}^{\phi} b_{i}^{l, k} \\
&+\sigma \sum_{m} W d_{m o}\left(1-\mu_{m}\right)+\sum_{m} w_{m}\left[d_{f} * R O\left(\frac{\psi_{p-t}}{24}\right)+d_{o} * R O\left(\frac{\psi_{p-t}}{10}\right)\right] . \\
& v\left(\psi_{p-t}\right)>\omega .
\end{aligned}
$$

Formula (20) shows that the network design or path optimization aims to minimize the total cost, which encompasses freight transport cost, freight storage cost, freight quality loss cost, and container cost.

In the multimodal transport network, only one transport mode is allowed between two adjacent nodes:

$$
\sum_{l \in L} a_{i, j}^{l}=1 \quad \forall(i, j) \in R, \forall l \text {. }
$$

At each node, only one mode conversion scheme is allowed, i.e., converting from mode $l$ to mode $k$ or sticking to mode 1 :

$$
\sum_{l, k \in L} b_{i}^{l, k}=1 \quad \forall i \in O, \forall l \text {. }
$$

The transport must be continuous:

$$
a_{i-1, i}^{l}+a_{i, i+1}^{k} \geq 2 b_{i}^{l, k} \quad \forall i \in O, \forall l .
$$

The mode conversion capability at node $i$ must be constrained by $W_{i}^{l, k}$ :

$$
\sum_{m} W_{m} b_{i}^{l, k} \leq W_{i}^{l, k}
$$

The maximum number $Q$ of mode conversions must be constrained by

$$
\sum_{i \in O} \sum_{l, k \in L} b_{i}^{l, k} \leq Q \forall i, l, k
$$

Let $\varphi_{i}^{l, k}$ be the time to convert mode $l$ to mode $k$ at node $i$. The arrival time of the freight choosing highway transport $(k=1)$ or railway transport $(k=2)$ at node $j$ should satisfy

$$
\left\{\begin{array}{l}
a_{i, j}^{k}\left(E_{i}+\phi_{i}^{l, k} \cdot b_{i}^{l, k}+\phi_{i, j}^{k}-E_{j}\right), k=1 \\
a_{i, j}^{k}\left(s_{i}^{k}+\phi_{i, j}^{k}-E_{j}\right), k=2
\end{array}\right.
$$

Let $\omega$ be the constraint on the satisfaction of consignor and consignee. The consignee's satisfaction with the delivery time must be constrained by
No return is allowed during the freight transport:

$$
a_{i, j}^{l} \geq 0, a_{j, i}^{l}=0 \text {. }
$$

The binary variables must be logically constrained:

$$
a_{i, j}^{l}, b_{i}^{l, k} \in\{0,1\} \forall i, j \in U, \forall l, k \in L \text {. }
$$

\section{Experiments and Results Analysis}

Figure 5 shows the distribution of multimodal transport volume in 2020. Monthly variation could be observed. From January to May, the freight volume was on the rise. From June to September, the freight volume was stable. Starting from October, the freight volume decreased, reaching the annual low in December.

Four core nodes were selected from the multimodal transport network. These nodes boast the largest freight flow and the most dense road network than other nodes. Figure 6 presents the freight volume distribution in the slack season and busy season at different core nodes. Among the four core nodes, nodes 1,2 , and 4 have a much greater freight volume in the busy season than in the slack season; node 3 sees a slight gap between the freight volumes of the two seasons: the volume in the slack season is slightly greater than that in the busy season.

A simulation was carried out to verify the effectiveness of our model. It is assumed that, one day, the multimodal freight transport network receives 28 shipment requests from five nodes (origins) A-E. Each request corresponds to a unique origin, destination, and freight volume. That is, the requests differ in both transport paths and volume. The requests from the same origin do not necessarily face the same constraints on shipment time, delivery time, and transport cost. Table 1 lists the time windows of freight services.

Currently, the multimodal freight transport network can utilize five origins and destinations, including origins A, C, 


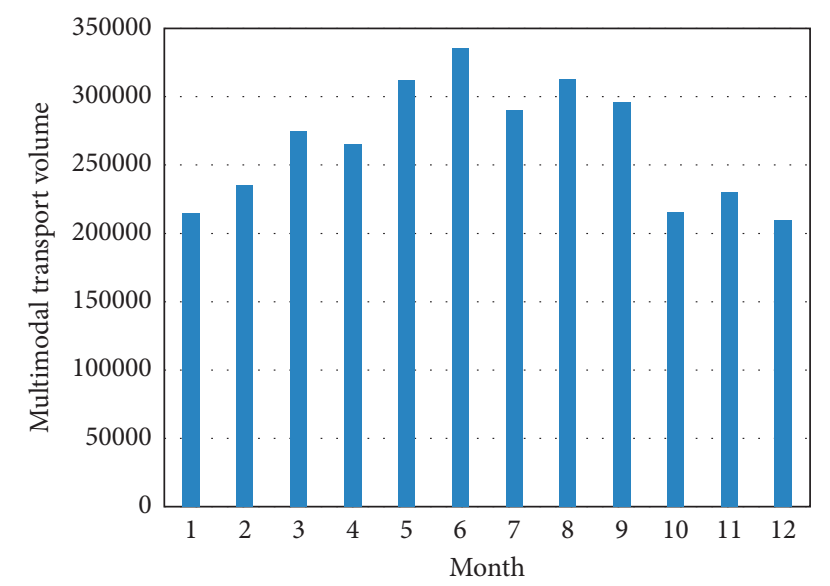

Figure 5: Distribution of multimodal transport volume in 2020.

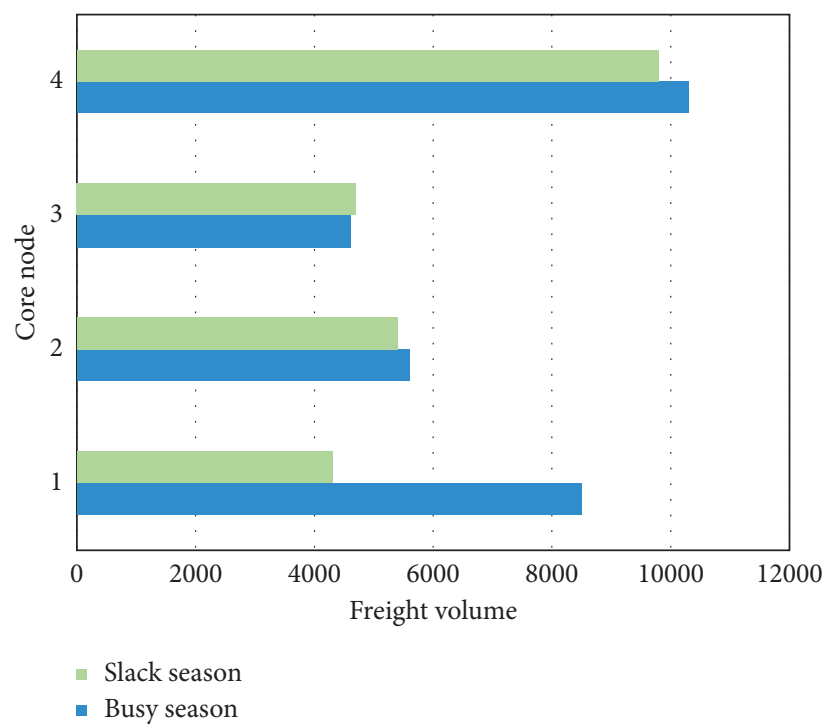

FIGURE 6: Freight volume distribution in the slack season and busy season at different core nodes. Note that node 4 faces a far smaller volume in the slack season than in the busy season, reflecting the strong purposefulness and seasonality of freight shipment by the consignor. During the busy season, more multimodal transport vehicles should be managed and deployed at the core nodes. During the slack season, these vehicles should be reduced at the core nodes. This is a necessary strategy for the planning, investment, and construction of the multimodal transport network. Reasonable planning, investment, and construction could reduce the operation cost of the multimodal freight transport network and ease the irrational distribution of vehicles.

TABle 1: Time windows of freight services.

\begin{tabular}{|c|c|c|c|c|c|c|c|}
\hline Freight service number & 1 & $2-3$ & $4-6$ & $7-8$ & 9-11 & $12-14$ & 15 \\
\hline Time window & {$[16,18]$} & {$[14,15]$} & {$[18,19]$} & {$[8,9]$} & {$[6,7]$} & {$[3,6]$} & {$[5,8]$} \\
\hline Latest delivery time & 35 & 33 & 36 & 24 & 21 & 18 & 23 \\
\hline Freight service number & $16-18$ & $19-20$ & $21-23$ & $24-25$ & $26-29$ & $30-32$ & \\
\hline Time window & {$[15,17]$} & {$[8,9]$} & {$[6,11]$} & {$[13,17]$} & {$[10,14]$} & {$[12,16]$} & \\
\hline Latest delivery time & 31 & 33 & 30 & 32 & 35 & 30 & \\
\hline
\end{tabular}

and $\mathrm{D}$ and destinations $\mathrm{B}$ and $\mathrm{E}$. Taking origin $\mathrm{A}$ and destination $\mathrm{B}$ as an example, $\mathrm{F}, \mathrm{J}$, and $\mathrm{H}$ are the transport nodes, with J being an airport. To complete the multimodal transport of the freight, F-J and J-H could choose between sea transport and airway transport; A-F and H-B could choose between highway transport and railway transport. Sea transport and airway transport could be arranged between some origins and destinations, but these sea or air routes have not entered operation between these nodes. Table 2 provides the data on transport paths.

Sea transport has a low freight cost. Normally, the cargo ships operate at $27-36 \mathrm{~km} / \mathrm{h}$. Here, the speed of sea transport is unified as $30 \mathrm{~km} / \mathrm{h}$. During the delivery period, the delivery time and shipment time were rounded to the nearest 
TABLE 2: Data on transport paths.

\begin{tabular}{|c|c|c|c|c|c|}
\hline Path & $\mathrm{A}-\mathrm{B}$ & $\mathrm{C}-\mathrm{B}$ & $\mathrm{D}-\mathrm{B}$ & D-E & A-E \\
\hline Number of window opening (days) & 3 & 2 & 4 & 4 & 3 \\
\hline Highway distance $(\mathrm{km})$ & 205 & 247 & 174 & 162 & 168 \\
\hline Transport time $(\mathrm{h})$ & 8 & 10 & 7 & 5.8 & 5.6 \\
\hline
\end{tabular}

TABle 3: Timetable of sea transport.

\begin{tabular}{|c|c|c|c|c|c|c|c|}
\hline Path & & & & & & G-J & \\
\hline Ship number & 1 & 2 & 3 & 4 & 1 & 2 & 3 \\
\hline Shipment time & $8: 30$ & $12: 35$ & $20: 10$ & $22: 05$ & $20: 15$ & $09: 45$ & $21: 30$ \\
\hline Delivery time & $13: 45$ & $17: 55$ & $1: 30$ & $3: 35$ & $1: 25$ & $15: 10$ & $3: 05$ \\
\hline Path & & & $J-D$ & & & & \\
\hline Ship number & 1 & 2 & 1 & 1 & 2 & & \\
\hline Shipment time & $10: 45$ & $20: 25$ & $18: 35$ & $5: 20$ & $14: 15$ & & \\
\hline Delivery time & $17: 45$ & $3: 15$ & $2: 35$ & $10: 20$ & $19: 15$ & & \\
\hline
\end{tabular}

TABle 4: Transport paths and time at node J.

\begin{tabular}{|c|c|c|c|c|c|}
\hline Transit node & $\begin{array}{l}\mathrm{F} \\
\mathrm{J}\end{array}$ & $\begin{array}{l}\mathrm{G} \\
\mathrm{J}\end{array}$ & $\begin{array}{c}\mathrm{J} \\
\mathrm{H}\end{array}$ & $\begin{array}{l}\mathrm{J} \\
\mathrm{D}\end{array}$ & $\begin{array}{l}\mathrm{J} \\
\mathrm{K}\end{array}$ \\
\hline Railway distance $(\mathrm{km})$ & - & 322 & - & 225 & - \\
\hline Railway time (h) & - & 4.7 & - & 2.8 & - \\
\hline Highway distance (km) & 415 & 321 & 357 & 226 & 268 \\
\hline Highway time $(\mathrm{h})$ & 5.3 & 4.5 & 4.6 & 2.7 & 3.5 \\
\hline Sea transport distance $(\mathrm{km})$ & 213 & 424 & 157 & - & 321 \\
\hline Sea transport time $(\mathrm{h})$ & 6.3 & 11.5 & 9.6 & - & 8.5 \\
\hline Airway distance $(\mathrm{km})$ & - & 317 & 254 & 387 & 154 \\
\hline Airway time (h) & - & 1.3 & 1.1 & 1.9 & 0.8 \\
\hline
\end{tabular}

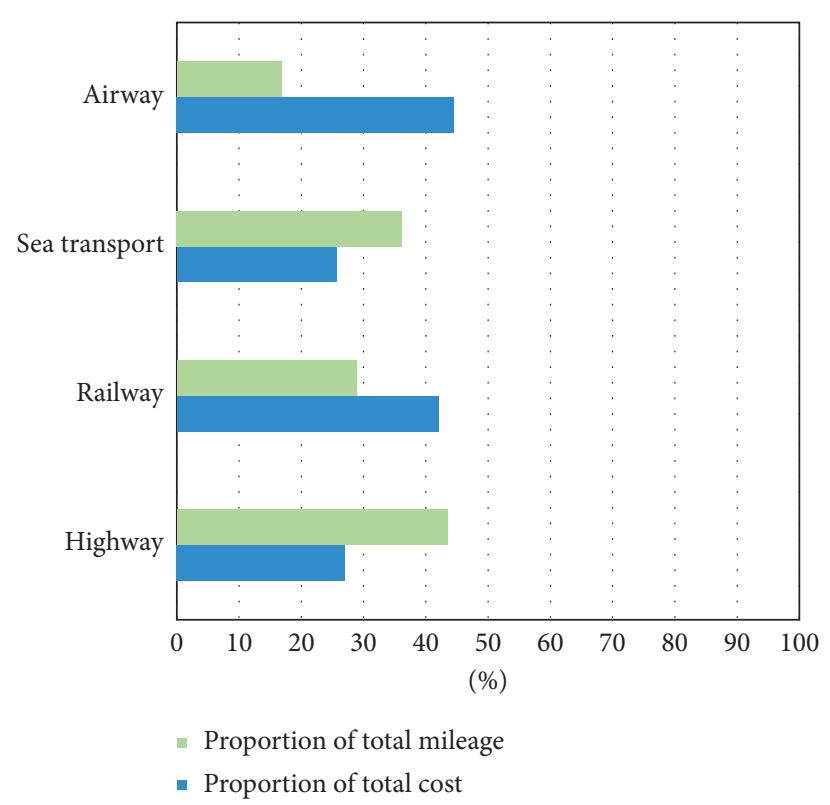

Figure 7: Proportion of different transport modes.

integer. These times can be estimated simply based on the timetable of all ships being used (Table 3).

The transport speeds of highway and railway transport were unified at $80 \mathrm{~km} / \mathrm{h}$ and $60 \mathrm{~km} / \mathrm{h}$, respectively. Node J is located in a special place. In 2016, a high-speed rail station was opened at that node. Therefore, node J can serve as the destination or a transit node for freights transported by highway, sea transport, airway, or railway. Table 4 shows the transport paths and time of some freights at node J. Figure 7 provides the proportion of different transport modes.

As shown in Figure 7, highway transport has a shorter mileage than railway transport and airway transport. The 
TABle 5: Optimal path decisions under different freight transport modes.

\begin{tabular}{|c|c|c|c|c|c|}
\hline Transport mode & Highway & Railway & Airway & Highway-railway & Highway-airway \\
\hline Path & $A-B-H-J-K-O$ & $A-B-E-H-F-K-O$ & $A-G-L-O$ & $A-E-G-J-L-M-T-O$ & $A-G-D-F-K-O$ \\
\hline Combination & 11111 & 333333 & 222 & 1133331 & 21111 \\
\hline Total cost (yuan) & 14519.65 & 51852.85 & 71561.56 & 34035.45 & 38013.42 \\
\hline Total time (h) & 38.25 & 23.36 & 12.58 & 27.34 & 26.52 \\
\hline Waiting time $(\mathrm{h})$ & 1 & 6.73 & 3.68 & 2.49 & 1.75 \\
\hline Time satisfaction & 0 & 0.085 & 1 & 0 & 0 \\
\hline
\end{tabular}

freight transport mileage divided by freight transport cost can characterize the conversion rate of the cost-effectiveness of a transport mode. For long-distance multimodal transport, highway transport is not as economic as railway transport or airway transport. To maximize profit and save cost, the multimodal freight transport platform should properly reduce the proportion of highway transport and increase that of the other transport modes during planning, investment, and construction.

To compare the effects of different transport modes on multimodal transport of freights with a specified delivery period, the optimal path decisions were derived for different modes, without time window constraint (Table 5). Compared with a single transport mode, the combinations of highway-railway and highway-airway are clearly superior, as they effectively enhance the time satisfaction of the consignee and reduce the total freight transport cost.

\section{Conclusions}

Based on big data analysis, this paper deeply explores the PDP and ICM of the multimodal transport network. Drawing on the big data of multiple freight services (e.g., railway, highway, waterway, and airway transport), a logit model was constructed to analyze the influencing factors and behavioral features of multimodal freight transport. Then, a PDO model was established for the multimodal transport network, and the multimodal transport decision-making was discussed in detail. Through experiments, the freight volume distributions were obtained for different core nodes in the slack and busy seasons, and the proportions of different transport modes were derived. The results show that the optimal freight transport effect could be achieved by properly reducing the proportion of highway transport and increasing that of the other transport modes. Finally, the optimal path decisions of different transport modes were obtained, which confirms the validity of our model.

During the follow-up research, it is important to further study personalized logistics services from the perspective of consumer demand and carry out pertinent analyses of risky situations and emergencies during the transport. Through the research, it is necessary to establish a risk identification, prevention, and control system, gradually enhance the safe management capability, and prepare corresponding security management strategies, which serve the logistics operations.

\section{Data Availability}

The data used to support the findings of this study are available from the corresponding author upon request.

\section{Conflicts of Interest}

The authors declare that they have no conflicts of interest.

\section{References}

[1] H. Lee and S. Choo, "Optimal decision-making process of transportation service providers in maritime freight networks," KSCE Journal of Civil Engineering, vol. 20, no. 2, pp. 922-932, 2016.

[2] I. Gil-Saura, G. Berenguer-Contri, and E. Ruiz-Molina, "Satisfaction and loyalty in B2B relationships in the freight forwarding industry: adding perceived value and service quality into equation," Transport, vol. 33, no. 5, pp. 1184-1195, 2018.

[3] V. Muerza, E. Larrodé, and J. M. Moreno-Jiménez, "Identification and selection of ICTs for freight transport in product service supply chain diversification," Industrial Management \& Data Systems, vol. 117, no. 7, pp. 1469-1484, 2017.

[4] W. C. Huang and B. Shuai, "Using improved entropy-cloud model to select high-speed railway express freight train service sites," Mathematical Problems in Engineering, vol. 2017, pp. 1-13, Article ID 7824835, 2017.

[5] M. Tamannaei, H. Zarei, and S. Aminzadegan, "A gametheoretic approach to the freight transportation pricing problem in the presence of intermodal service providers in a competitive market," Networks and Spatial Economics, vol. 21, no. 1, pp. 123-173, 2021.

[6] Z. Lan, S. He, and Y. Xu, "Combining Benders decomposition and column generation for scheduled service network design problem in rail freight transportation," Transportmetrica: Transportation Science, vol. 17, no. 4, pp. 1382-1404, 2021.

[7] L. Kuttner, "Ant colony optimization for a network design problem in freight service," MKWI 2018 - Multikonferenz Wirtschaftsinformatik, vol. 2018, pp. 1923-1934, 2018.

[8] R. Molfino, M. Zoppi, G. G. Muscolo et al., "An electromobility system for freight service in urban areas," International Journal of Electric and Hybrid Vehicles, vol. 7, no. 1, pp. 1-21, 2015.

[9] D. Wang and N. Wang, "Quantum computation based bundling optimization for combinatorial auction in freight service procurements," Computers \& Industrial Engineering, vol. 89, pp. 186-193, 2015.

[10] Y. Lu, X. Pei, C. Zhang, H. Luo, B. Liu, and Z. Ma, "Design of multimodal transport path optimization model and dual pheromone hybrid algorithm," Journal Européen des Systèmes Automatisés, vol. 52, no. 5, pp. 477-484, 2019.

[11] M. Le Pira, L. A. Tavasszy, G. H. d. A. Correia, M. Ignaccolo, and G. Inturri, "Opportunities for integration between Mobility as a Service (MaaS) and freight transport: a conceptual model," Sustainable Cities and Society, vol. 74, p. 103212, 2021.

[12] P. X. Bai, Q. Q. Wu, Q. Li, L. Zhang, Y. H. Jiang, and B. Chen, "The value cocreation influence mechanism of network freight 
transport platform in IoT-based environments: under the service-dominant logic," Wireless Communications and Mobile Computing, vol. 2021, pp. 1-13, Article ID 8492759, 2021.

[13] L. Gao and H. Dou, "Inventory management of railway logistics park based on artificial neural network," Journal Européen des Systèmes Automatisés, vol. 53, no. 5, pp. 715-723, 2020.

[14] A. Garcia-Martinez, R. Cascajo, S. R. Jara-Diaz, S. Chowdhury, and A. Monzon, "Transfer penalties in multimodal public transport networks," Transportation Research Part A: Policy and Practice, vol. 114, pp. 52-66, 2018.

[15] S. S. Mogre and E. F. Koslover, "Multimodal transport and dispersion of organelles in narrow tubular cells," Physical Review, vol. 97, no. 4, p. 042402, 2018.

[16] X. Y. Chen and I. Kim, "Modelling rail-based park and ride with environmental constraints in a multimodal transport network," Journal of Advanced Transportation, vol. 2018, no. 1443, pp. 1-15, Article ID 2310905, 2018.

[17] Y.-C. Tsao and V. T. Linh, "Seaport- dry port network design considering multimodal transport and carbon emissions," Journal of Cleaner Production, vol. 199, pp. 481-492, 2018.

[18] F. Zhang, N. Zheng, H. Yang, and N. Geroliminis, "A systematic analysis of multimodal transport systems with road space distribution and responsive bus service," Transportation Research Part C: Emerging Technologies, vol. 96, pp. 208-230, 2018.

[19] Z. Tian, H. Nakamura, M. Boltze, and E. Chung, "Editors' notes: special issue on innovative intersection design and control for serving multimodal transport users," Transportation Research Part C: Emerging Technologies, vol. 86, pp. 639-640, 2018.

[20] T. J. Zhao, J. H. Wang, and J. H. Zhang, "Real-time multimodal transport path planning based on a pulse neural network model," International Journal of Simulation and Process Modelling, vol. 12, no. 3-4, pp. 356-361, 2017.

[21] P. Colpaert, M. Van Compernolle, N. Walravens et al., "Open transport data for maximising reuse in multimodal route planners: a study in Flanders," IET Intelligent Transport Systems, vol. 11, no. 7, pp. 397-402, 2017.

[22] A. E. Coronado Mondragon, C. E. Coronado Mondragon, and E. S. Coronado, "ICT adoption in multimodal transport sites: investigating institutional-related influences in international seaports terminals," Transportation Research Part A: Policy and Practice, vol. 97, pp. 69-88, 2017.

[23] J. Li, Q. Chen, J. Sun, J. Zhang, and C. Zuo, "Multimodal computational microscopy based on transport of intensity equation," Journal of Biomedical Optics, vol. 21, no. 12, p. 126003, 2016.

[24] R. Costa, R. Jardim-Goncalves, P. Figueiras, M. Forcolin, M. Jermol, and R. Stevens, "Smart cargo for multimodal freight transport: when "')"',", IFAC-PapersOnLine, vol. 49, no. 12, pp. 121-126, 2016.

[25] G. Lämmel, M. Chraibi, A. U. K. Wagoum, and B. Steffen, "Hybrid multimodal and intermodal transport simulation: case study on large-scale evacuation planning," Transportation Research Record, vol. 2561, pp. 1-8, 2016.

[26] J. Liu, Q. Y. Peng, and Y. Yin, "Multimodal transportation route planning under low carbon emissions background," Jiaotong Yunshu Xitong Gongcheng Yu Xinxi/Journal of Transportation Systems Engineering and Information Technology, vol. 18, no. 6, pp. 243-249, 2018.

[27] M. Mnif and S. Bouamama, "A multi-objective formulation for multimodal transportation network's planning problems," in Proceedings of the 2017 IEEE International Conference on
Service Operations and Logistics, and Informatics, pp. 144-149, SOLI, Bari, Italy, 18-20 Sept. 2017.

[28] M. Haqqani, X. Li, and X. Yu, "An evolutionary multi-criteria journey planning algorithm for multimodal transportation networks," Lecture Notes in Computer Science, vol. 10142, pp. 144-156, 2017. 